\title{
EFFECT OF KNITTING PARAMETERS ON MOISTURE MANAGEMENT AND AIR PERMEABILITY OF INTERLOCK FABRICS
}

\author{
Ahsan Nazir*, Tanveer Hussain, Faheem Ahmad, Sajid Faheem \\ Faculty of Engineering and Technology, National Textile University Sheikhupura Road Faisalabad (37610), Pakistan. \\ E-mail: ahsanpd@gmail.com
}

\begin{abstract}
:
The aim of this study was to investigate the effect of knitting parameters on the moisture management and air permeability of the interlock fabrics. Samples were produced at two different knitting gauges, each with three different stitch lengths. It was found that the fabric mass per square metre increases by increasing machine gauge and decreasing the stitch length, whereas the fabric thickness and porosity increase at these settings. It was further concluded that the loosely knitted fabric samples with higher amount of entrapped air exhibit good air permeability but poor moisture management properties.
\end{abstract}

\section{Keywords:}

Knitted fabric; moisture management; air permeability; interlock; comfort

\section{Introduction}

Consumers of clothes demand high levels of comfort, design and easy-care in their everyday bodywear. Comfort is usually regulated through interaction of human body with its microclimate and clothing. It is generally determined from a combination of sensorial, psychological and thermophysiological properties [1]. The human body generates metabolic heat and sweat is produced as a part of the natural mechanism to dissipate the extra heat not needed by the body. An uncovered human body can control the heat loss during strenuous activity, as sweat evaporates quite easily, thus leaving no accumulated sweat when that activity stops. Evaporated sweat carries body heat away, thus cooling it down [2].

However, clothes can act as a barrier to the body heat and moisture loss. It is, therefore, necessary to wear such clothes that support the body achieving thermal and moisture equilibrium with its environment and generate a comfortable microclimate next to the skin [3]. This is particularly crucial in order to enhance the performance of the wearer in applications like sports and active wear, as clothes with undesirable thermal, moisture and air resistance properties not only decrease the comfort level but also affect the body performance [4]. Textile fabrics with excellent moisture management and heat control properties are available and are widely used for different types of clothing. These fabrics are claimed to have excellent comfort and performance properties due to their quick drying rates and efficient movement of moisture away from the skin with excellent breathability [5-7].

Knitted fabrics are widely used in sportswear due to their excellent stretch and recovery, porosity, air permeability, softness and warmth. Several research studies have been conducted in the past concerning performance, moisture management and thermal comfort aspects of knitted fabrics [8-11]. Kane et al. [12] studied the effect of fabric density on water absorption properties of fabrics. They observed that double pique fabric, which has greater density than single jersey fabrics, shows better water drop absorption. However, the authors did not study the interlock structure and the effect of knitting machine gauge. Ibrahim et al. [13] studied the effect of knitting structure and finishing treatments on the comfort properties of textiles. They concluded that single jersey fabric takes longer to absorb water droplet as compared with single pique fabrics. It was observed that thick knitted fabric gave warmer sense [14]. Moreover, it was found after a comparative study of different knitted structures that the open construction 3D eyelet fabric has better water vapour permeability than that of micromesh, pique and mock rib structure [15]. Transmission of liquid moisture has also been investigated for towels and it has been found that as the thickness of fabric or fibre volume increases, more resistance is offered to moisture transmission [16].

The knitting parameters and the type of structure not only affect the comfort but also the performance properties of the knitted fabrics [17]. Knitting machine gauge and the knitting stitch length are the two fundamental knitting parameters that directly affect all structure related properties of the knitted fabric $[11,18]$. Singh et al. [19] studied the effect of stitch length of jersey fabric and reported that stitch length affects its shrinkage in a direct manner. Available literature does not reveal the effect of knitting stitch length and machine gauge on the 3D moisture management and air permeability of the interlock knitted fabrics. The aim of this work is to fill this gap by investigating these key thermo-physiological comfort properties of the interlock fabrics. 


\section{Experimental}

\section{Materials and method}

A $100 \%$ cotton combed yarn spun with 25 tex linear density was purchased from Sapphire Fibres Pakistan. The chemicals used for the scouring and bleaching of the knitted samples comprised caustic soda (provided by Engro Chemical Ltd.), hydrogen peroxide (procured from Sitara Chemicals Ltd.), bleaching stabiliser (Stabilizer CT provided by Chromatex Chemicals Ltd.), detergent and wetting agent (Hostapal NI extra provided by Clariant Pakistan Ltd.) and sequestering agent (Alkaquest AM 700 procured from Alka Chemicals Pakistan Ltd.), respectively. All these chemicals were of industrial/ commercial grade.

\section{Knitting of Samples}

The interlock fabric samples were knitted on a Mayer and Cie double knit machine with 20 and 18 (needles per inch) gauges, while $0.31,0.32$ and $0.33 \mathrm{~cm}$ knitting stitch lengths (also called loop length) were used at each machine gauge.

\section{Scouring and Bleaching}

All the knitted fabric samples were scoured and bleached together as a single processing lot in Gaston County pressurised winch machine. Samples were processed at $110^{\circ} \mathrm{C}$ for 15 minute with $4.0 \mathrm{~g} / \mathrm{L}$ caustic soda, $6.0 \mathrm{~g} / \mathrm{L}$ hydrogen peroxide, $0.5 \mathrm{~g} / \mathrm{L}$ Stabilizer CT, $2.0 \mathrm{~g} / \mathrm{L}$ Hostapal NI extra and $0.4 \mathrm{~g} / \mathrm{L}$ of Alkaquest AM 700 . The treated fabric samples were then hot washed, rinsed and tumble dried.

\section{Testing and Evaluation}

The testing of fabric samples was performed using five replicates of each sample. Fabric thickness was measured using fabric thickness tester (by SDL Atlas) as per ASTM D1777 standard test procedure. Fabric mass per square metre was determined according to ASTM D3776. Moisture management properties of fabric samples were tested using Moisture Management Tester (MMT, by SDL Atlas) according to AATCC Test Method 195-2009. The properties defined in this method include wetting times, absorption rates, spreading speeds and wetted radius of top and bottom surfaces. Using these basic properties, cumulative one-way transport index and overall moisture management capacity are determined. Cumulative one-way transport index determines the amount of moisture transported from top to bottom surface of fabric, calculated by the difference in moisture contents of the two surfaces. The overall moisture management capacity determines the overall ability of the fabric to manage the moisture and is calculated from moisture absorption rate and spreading speed of bottom surface and cumulative one-way transport index [20]. To determine the moisture management capability of fabric, the fabric specimens were placed between top and bottom concentric sets of moisture sensors of the MMT. A predefined amount of test-water (representing synthetic sweat) was introduced at the top side of the fabric by a pump, and the test-water was then transferred to the fabric specimens in three directions: spreading outwards on the top layer of the fabric, transferring from the top fabric side to the bottom fabric side and spreading outwards on the bottom side of the fabric. The change in water content in the top and bottom layer was then detected by the moisture sensors and recorded by the connected computer.

Air permeability was measured using air permeability tester (by SDL Atlas) following the standard test method ASTM D737. Fabric porosity was determined using equations (1) and (2).

$$
\text { Porosity }=1-(\rho b / \rho s)
$$

where $\rho b$ is the fabric density (g.cm-3) and $\rho$ is the fibre density $(\mathrm{g} \mathrm{cm}-3)$.

Fabric density $=$ Fabric weight $/$ Fabric thickness $(2)$

Here, fabric volume density is in ${\mathrm{g} . \mathrm{cm}^{-3}}^{3}$, fabric weight is in $\mathrm{g.cm}$ ${ }^{2}$ and fabric thickness is in $\mathrm{cm}$.

\section{Results and Discussion}

\section{Physical Properties}

The effect of knitting parameters on the physical properties of interlock fabrics and $p$-values from analysis of variance (ANOVA) for these effects are given in Tables 1 and 2, respectively. ANOVA shows that input variables significantly affect the physical properties ( $p$-values $<0.05$ ). Figure 1 explains that an increase in knitting stitch length results in decease in fabric mass per square metre $\left(\mathrm{g} / \mathrm{m}^{2}\right.$; GSM) and increase in fabric thickness. The fabric produced with the lowest knitting machine gauge (needles/inch) and the highest stitch length has the highest thickness and the lowest GSM, whereas the fabric produced with the highest machine gauge and the lowest stitch length has the highest GSM. With higher stitch length and lower machine gauge, number of knitting loops per unit area decreases leading to decrease in amount of yarn present in the unit area, which results in decrease in fabric mass per square metre. With less amount of yarn per unit area, the tightness factor (ratio of the fabric area covered by the yarn to the total fabric area) is less leading to higher fabric bulk and thickness, which is further accentuated because of higher shrinkage during fabric processing.

The effect of knitting parameters on the density and the porosity of the interlock fabric is shown in Figure 2. It is clear that with increase in stitch length, the density of the fabric decreases. The density and the porosity of the fabrics are inversely proportional. The fabric produced with the lowest machine gauge and the highest stitch length gives the highest porosity and the lowest density because of the lowest GSM and the highest thickness at these settings.

\section{Moisture Management Properties}

The knitting parameters primarily affect the physical properties of the knitted fabric such as GSM, thickness, density and 
Table 1. Knitting parameters and the physical properties of the knitted fabrics

\begin{tabular}{|c|c|c|c|c|c|c|c|c|c|c|c|}
\hline \multicolumn{4}{|c|}{ Knitting Parameters } & \multicolumn{8}{|c|}{ Physical Properties of the Knitted Fabrics } \\
\hline \multirow{2}{*}{$\begin{array}{l}\text { Machine } \\
\text { Gauge } \\
\text { (Needles/ } \\
\text { inch) }\end{array}$} & \multirow{2}{*}{$\begin{array}{l}\text { Stitch } \\
\text { Length } \\
\text { (cm) }\end{array}$} & \multirow{2}{*}{$\begin{array}{l}\text { Yarn } \\
\text { Linear } \\
\text { Density } \\
\text { (tex) }\end{array}$} & \multirow{2}{*}{$\begin{array}{l}\text { Cover } \\
\text { Factor }\end{array}$} & \multicolumn{2}{|c|}{$\begin{array}{l}\text { Mass per sq. } \\
\text { metre }\left(\mathbf{g} / \mathbf{m}^{2}\right)\end{array}$} & \multicolumn{2}{|c|}{ Thickness (mm) } & \multicolumn{2}{|c|}{ Density $\left(\mathbf{g} / \mathrm{cm}^{3}\right)$} & \multicolumn{2}{|c|}{ Porosity } \\
\hline & & & & $\begin{array}{c}\text { Average } \\
\text { value }\end{array}$ & SD & $\begin{array}{c}\text { Average } \\
\text { value }\end{array}$ & SD & $\begin{array}{c}\text { Average } \\
\text { value }\end{array}$ & SD & $\begin{array}{c}\text { Average } \\
\text { value }\end{array}$ & SD \\
\hline 20 & 0.31 & 25 & 16.13 & 373 & 4.25 & 1.268 & 1.01 & 0.294 & 0.71 & 0.809 & 0.04 \\
\hline 20 & 0.32 & 25 & 15.63 & 365 & 1.62 & 1.272 & 0.77 & 0.287 & 0.59 & 0.814 & 0.13 \\
\hline 20 & 0.33 & 25 & 15.15 & 359 & 5.49 & 1.308 & 1.37 & 0.274 & 0.04 & 0.822 & 0.01 \\
\hline 18 & 0.31 & 25 & 16.13 & 371 & 6.25 & 1.240 & 0.73 & 0.299 & 0.74 & 0.806 & 0.69 \\
\hline 18 & 0.32 & 25 & 15.63 & 363 & 0.39 & 1.268 & 0.64 & 0.286 & 0.37 & 0.814 & 0.91 \\
\hline 18 & 0.33 & 25 & 15.15 & 353 & 1.83 & 1.340 & 0.34 & 0.263 & 0.00 & 0.829 & 0.94 \\
\hline
\end{tabular}

$\mathrm{SD}=$ Standard deviation

Table 2. P-values from ANOVA for effect of input variables on physical properties

\begin{tabular}{|c|c|c|c|}
\hline & Stitch Length & Gauge & Stitch Length $\times$ Gauge \\
\hline Fabric mass per square metre & 0.064 & 0.001 & 0.091 \\
\hline Thickness & 0.038 & 0.057 & 0.183 \\
\hline Density & 0.073 & 0.046 & 0.018 \\
\hline Porosity & 0.000 & 0.062 & 0.299 \\
\hline
\end{tabular}

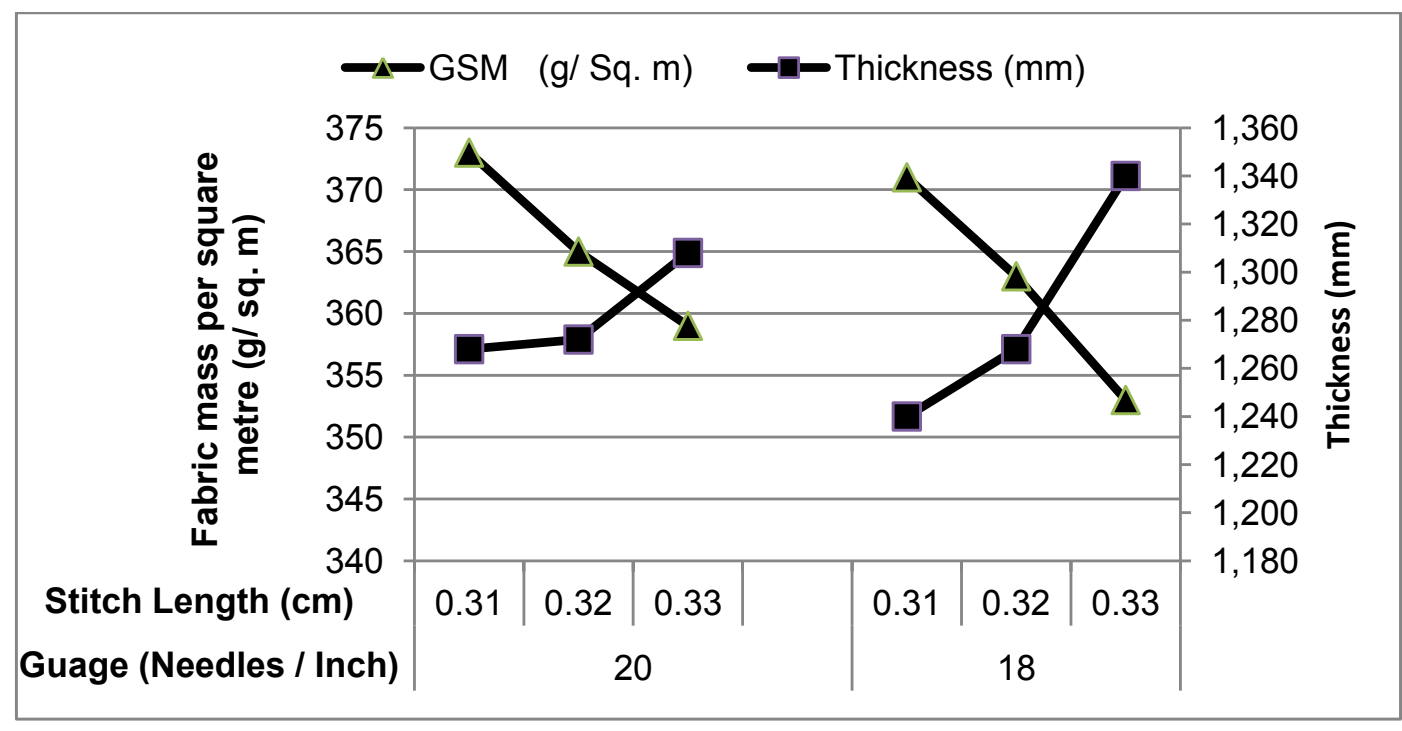

Figure 1. Effect of knitting parameters on GSM and thickness of the interlock fabric.

porosity, which in turn affect the mechanical performance and comfort properties of the fabric. The effect of knitting parameters on the two important comfort aspects of interlock fabrics, i.e. moisture management and air permeability, is given in Table 3. P-values from ANOVA for effect of selected input parameters on these aspects are shown in Table 4. The $p$-values in Table 4 show that input factors significantly affect the comfort properties ( $p$-value $<0.05$ ).
Figure 3 illustrates the effect of knitting parameters on the fabric wetting time at the top $\left(\mathrm{WT}_{\mathrm{T}}\right)$ and bottom fabric side $\left(\mathrm{WT}_{\mathrm{B}}\right)$. Wetting time is the time in seconds taken by a measured drop of test-water for initial wetting of the fabric. Top fabric surface refers to that side of the fabric which initially comes in contact with the test-water drop and represents the side that would come in contact with the skin of a wearer and first encounter the wearer's perspiration. 


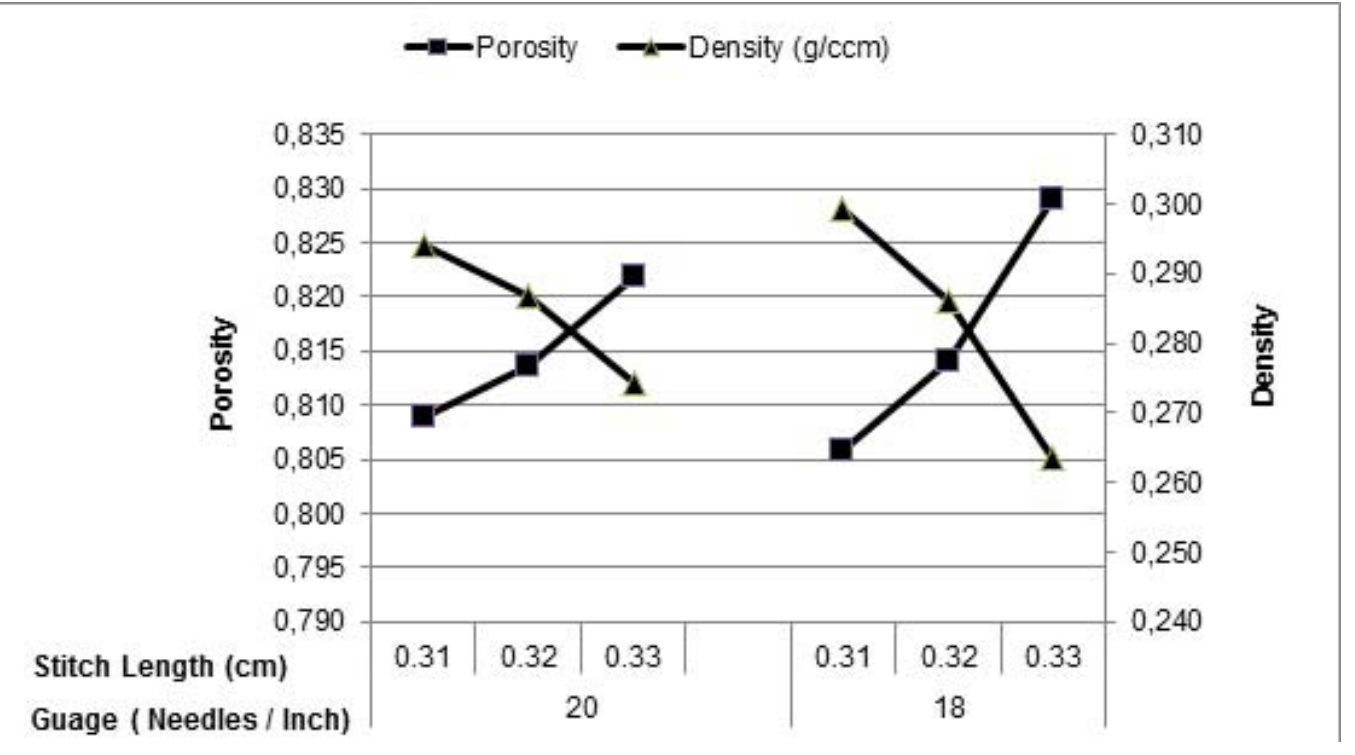

Figure 2. Effect of knitting parameters on the density and porosity of the interlock fabric.

Table 3. Moisture management and air permeability of the knitted fabrics.

\begin{tabular}{|c|c|c|c|c|c|c|c|c|c|c|c|c|}
\hline $\begin{array}{c}\text { Machine } \\
\text { Gauge } \\
\text { (Needles/ } \\
\text { inch) }\end{array}$ & $\begin{array}{l}\text { Stitch } \\
\text { Length } \\
\text { (cm) }\end{array}$ & & WTT & WTB & ART & ARB & MWRT & MWRB & SST & SSB & OMMC & $\begin{array}{c}\text { Air } \\
\text { Permeability } \\
\text { (mm/sec.) }\end{array}$ \\
\hline \multirow{6}{*}{20} & \multirow[t]{2}{*}{0.31} & $\begin{array}{c}\text { Average } \\
\text { value }\end{array}$ & 11.32 & 12.04 & 69.76 & 67.30 & 15.00 & 15.00 & 1.05 & 1.13 & 0.19 & 61.00 \\
\hline & & SD & 1.89 & 1.04 & 6.19 & 6.95 & 0.00 & 2.04 & 0.08 & 0.12 & 0.24 & 2.20 \\
\hline & \multirow[t]{2}{*}{0.32} & $\begin{array}{c}\text { Average } \\
\text { value }\end{array}$ & 9.55 & 9.46 & 46.22 & 40.77 & 12.00 & 12.00 & 1.01 & 1.00 & 0.16 & 62.00 \\
\hline & & SD & 1.67 & 1.21 & 4.80 & 4.99 & 0.00 & 0.00 & 0.03 & 0.07 & 0.21 & 1.23 \\
\hline & \multirow[t]{2}{*}{0.33} & $\begin{array}{c}\text { Average } \\
\text { value }\end{array}$ & 11.12 & 10.35 & 45.87 & 20.55 & 10.00 & 12.50 & 0.83 & 0.82 & 0.13 & 62.50 \\
\hline & & SD & 3.12 & 2.44 & 8.02 & 9.03 & 0.00 & 0.00 & 0.05 & 0.12 & 0.13 & 3.93 \\
\hline \multirow{6}{*}{18} & \multirow[t]{2}{*}{0.31} & $\begin{array}{c}\text { Average } \\
\text { value }\end{array}$ & 12.98 & 13.89 & 52.77 & 73.24 & 12.00 & 12.00 & 0.86 & 0.88 & 0.18 & 65.00 \\
\hline & & SD & 1.14 & 1.14 & 4.28 & 4.71 & 0.00 & 2.23 & 0.05 & 0.08 & 0.28 & 0.28 \\
\hline & \multirow{2}{*}{0.32} & $\begin{array}{c}\text { Average } \\
\text { value }\end{array}$ & 18.52 & 17.88 & 55.37 & 50.56 & 10.00 & 10.00 & 0.42 & 0.44 & 0.12 & 67.00 \\
\hline & & SD & 1.08 & 4.06 & 10.06 & 5.69 & 0.00 & 2.04 & 0.09 & 0.17 & 0.22 & 2.32 \\
\hline & \multirow[t]{2}{*}{0.33} & $\begin{array}{c}\text { Average } \\
\text { value }\end{array}$ & 19.24 & 19.00 & 35.21 & 32.33 & 10.00 & 10.00 & 0.55 & 0.57 & 0.08 & 68.00 \\
\hline & & SD & 2.88 & 1.40 & 1.22 & 2.42 & 0.00 & 0.00 & 0.05 & 0.05 & 0.21 & 0.47 \\
\hline
\end{tabular}

$W T_{T}=$ Wetting time of the top surface; $W_{B}=$ Wetting time of the bottom surface; $A R_{T}=$ Absorption rate of top surface; $A R_{B}=A b s o r p t i o n$ rate of bottom surface; $M W R_{T}=$ Maximum wetted radius for top surface; $M W R_{B}=$ Maximum wetted radius for bottom surface; $S_{S}=S$ spreading speed for top surface; $\mathrm{SS}_{\mathrm{B}}=$ Spreading speed for bottom surface; OMMC = Overall moisture management capacity; $\mathrm{SD}=\mathrm{Standard}$ deviation

It is clear from Figure 3 that wetting time increases due to increase in stitch length and decrease in machine gauge for the interlock fabric. Knitting of fabric at lower gauge and higher stitch length result in a loose structure with larger air gaps. Fabric surface wetting is the replacement of fabric-air interface with fabric-water interface. In loose structures, the total hygroscopic cotton fibre surface per unit fabric area is less due to intermittent larger air gaps as compared with that in the tighter fabric structure. Hence, the water adsorption and wetting time are greater in case of loose fabric structures comprising hygroscopic cotton fibres.

The loosely knitted cotton interlock structures not only take longer time in initial wetting/adsorption, but their liquid moisture absorption rate is also lower, as shown in Figure 4. Absorption rate is the average speed at which the test-water drop is absorbed by the fabric after initial wetting. The absorption is related to the tendency of the fabric to allow passing water 
Table 4. P-values from ANOVA for effect of input variables on comfort properties.

\begin{tabular}{|c|c|c|c|}
\hline Comfort Properties & Stitch Length & Gauge & Stitch Length $\times$ Gauge \\
\hline WTT & 0.046 & 0.000 & 0.002 \\
\hline WTB & 0.048 & 0.001 & 0.008 \\
\hline ART & 0.012 & 0.072 & 0.062 \\
\hline ARB & 0.046 & 0.043 & 0.107 \\
\hline MWRT & 0.024 & 0.039 & 0.011 \\
\hline MWRB & 0.068 & 0.044 & 0.340 \\
\hline SSB & 0.056 & 0.013 & 0.016 \\
\hline OMMC & 0.038 & 0.012 & 0.033 \\
\hline Air Permeability (mm/sec.) & 0.039 & 0.072 & 0.077 \\
\hline
\end{tabular}

$\mathrm{WT}_{\mathrm{T}}=$ Wetting time of the top surface; $\mathrm{WT}_{\mathrm{B}}=$ Wetting time of the bottom surface; $A R_{T}=$ Absorption rate of top surface; $A R_{B}=A b s o r p t i o n$ rate of bottom surface; $M_{W} R_{T}=$ Maximum wetted radius for top surface; $M_{W} R_{B}=$ Maximum wetted radius for bottom surface; $S_{T}=S$ spreading speed for top surface; $\mathrm{SS}_{\mathrm{B}}=$ Spreading speed for bottom surface; OMMC = Overall moisture management capacity

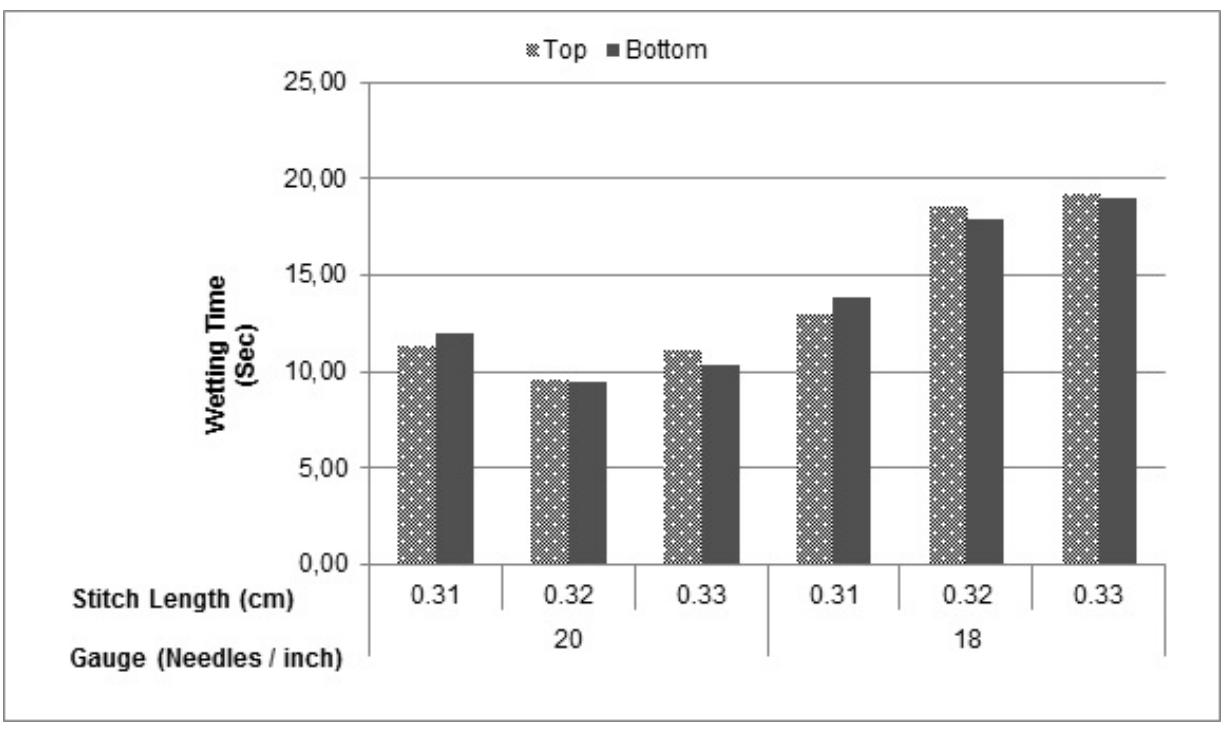

Figure 3. Effect of knitting parameters on wetting times

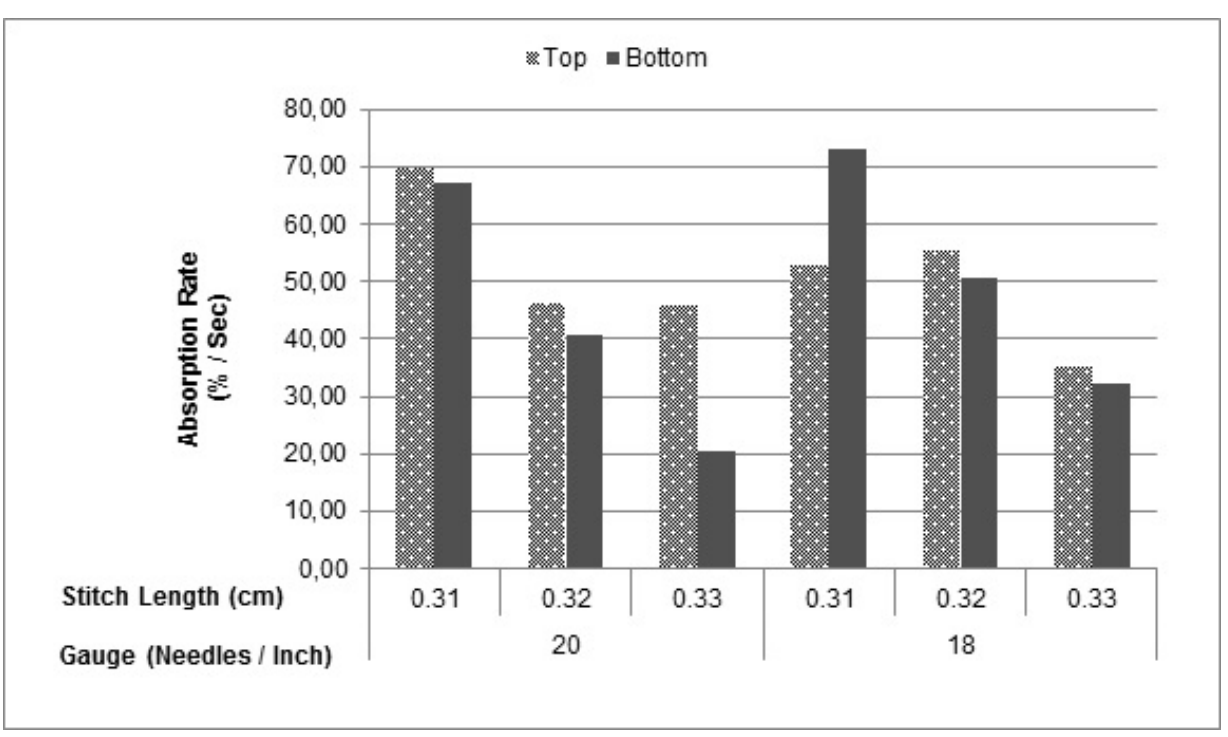

Figure 4. Effect of knitting parameters on absorption rates 
through the inter-yarn, inter-fibre and intra-fibre spaces. Loose structures have more air entrapped in inter-yarn and inter-fibre spaces before wetting which may resist the water movement initiation in the inter-yarn and inter-fibre spaces.

Furthermore, in case of a loose structure, less number of total fibres and yarn is present per unit fabric area leading to less number of total hygroscopic fibres and capillaries in the fabric structure. In tighter structures, number of capillaries (with smaller diameters) are more per unit area as compared with that in the loose structure resulting in better capillary action due to higher capillary pressure for quicker absorption. Due to the same reasons, the water spreading speed and the maximum wetted radius in the fabric are also lower for fabric with higher stitch length i.e. with loose structure as shown in Figures 5 and 6. Spreading speed is the accumulated rate of spreading of test-water at the top $\left(\mathrm{SS}_{\mathrm{T}}\right)$ and bottom fabric surfaces $\left(\mathrm{SS}_{\mathrm{B}}\right)$ from the centre of the test specimen where the test water is dropped to spread outwards to the respective maximum wetted radii, $M W R_{\mathrm{T}}$ and $M W R_{\mathrm{B}}$.

\section{Air Permeability}

The effect of knitting parameters on the air permeability of the knitted fabric is shown in Figure 7. It is clear that the air permeability of the interlock fabric increases with the increase

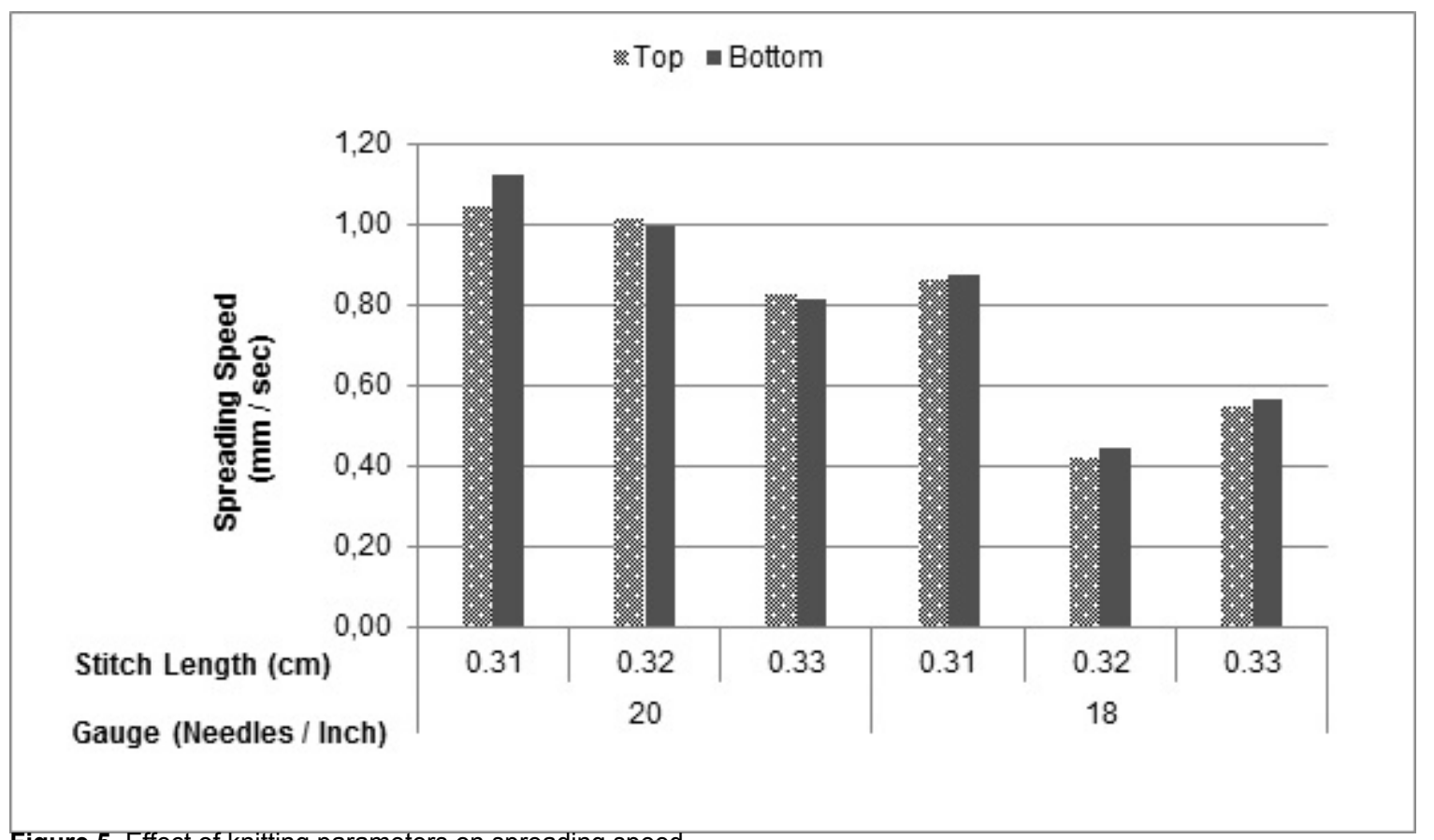

Figure 5. Effect of knitting parameters on spreading speed

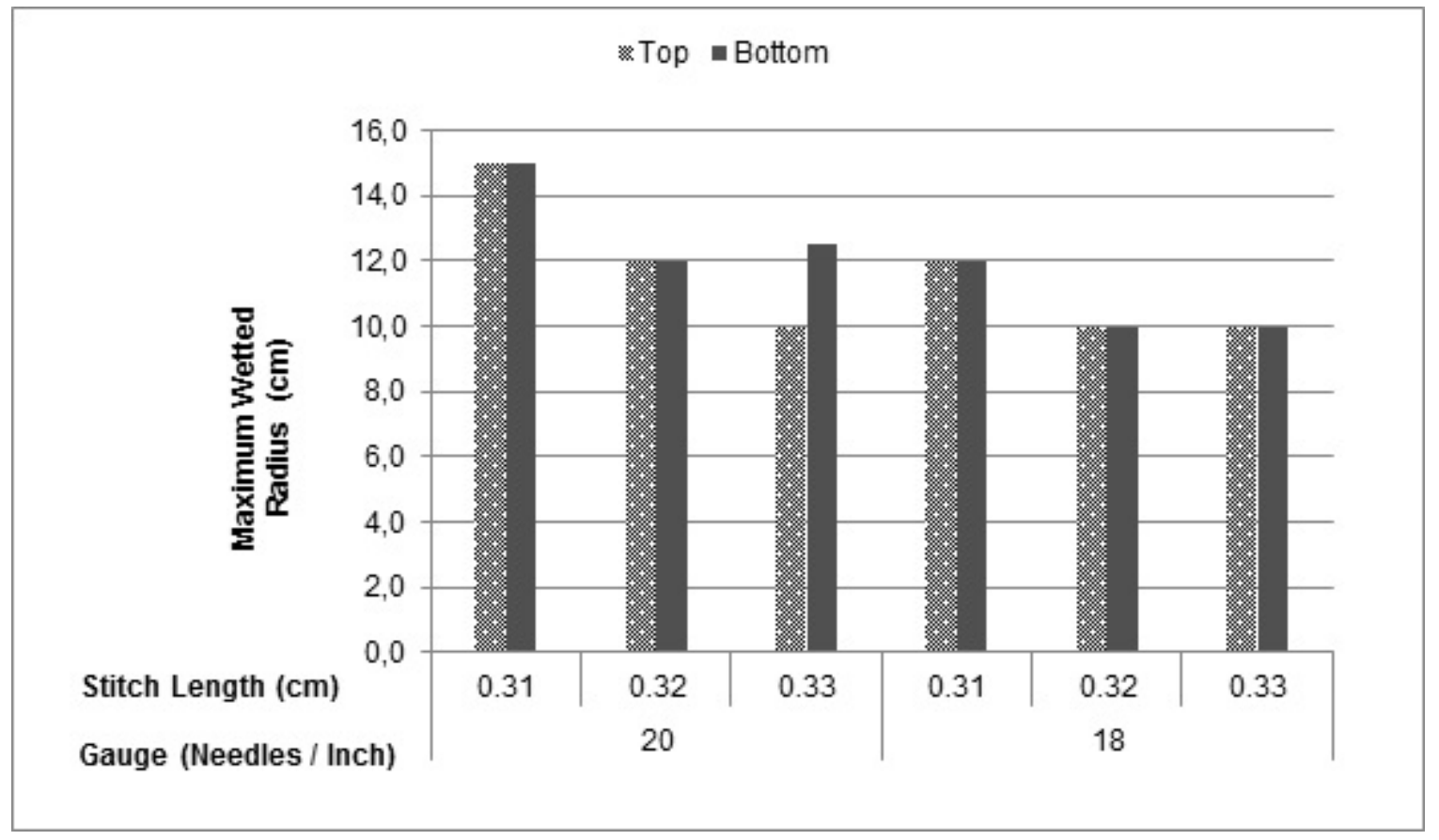

Figure 6. Effect of knitting parameters on maximum wetted radius 
in stitch length and decrease in the machine gauge. Loose knitted structures are more permeable to air owing to their higher porosity and lower density [21,22].

If we compare the air permeability trends vis-à-vis overall moisture management capability (OMMC) of the fabric as given in Figure 8, it can be observed that the trends are almost opposite to each other. This means that if we try to improve the air permeability of the interlock fabric by making a porous structure with less gauge and higher stitch length, overall moisture management capability of the fabric will decrease and vice versa. Overall moisture management capacity, as mentioned above, is based on three attributes, i.e. moisture absorption rate at the bottom of the fabric $\left(A R_{B}\right)$, spreading speed at the bottom $\left(\mathrm{SS}_{\mathrm{B}}\right)$ and accumulative one-way transport of the liquid moisture from the top to the bottom of the fabric. It could be an interesting future work to develop fabrics with simultaneous good air permeability and good overall moisture management capability.

\section{Conclusions}

It was concluded from this study that increase in knitting stitch length and decrease in knitting machine gauge result in decrease in the fabric GSM and the fabric density accompanied with

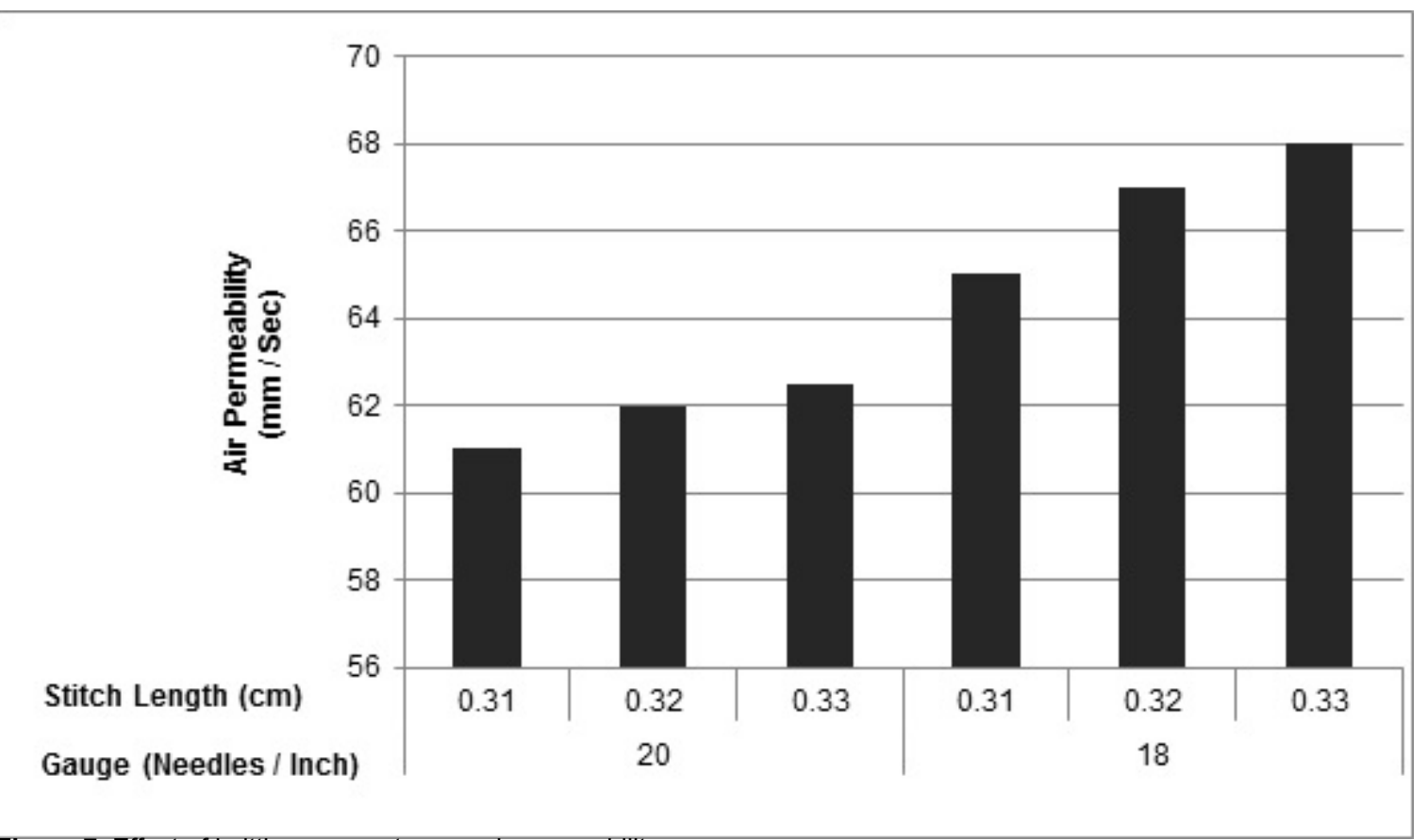

Figure 7. Effect of knitting parameters on air permeability

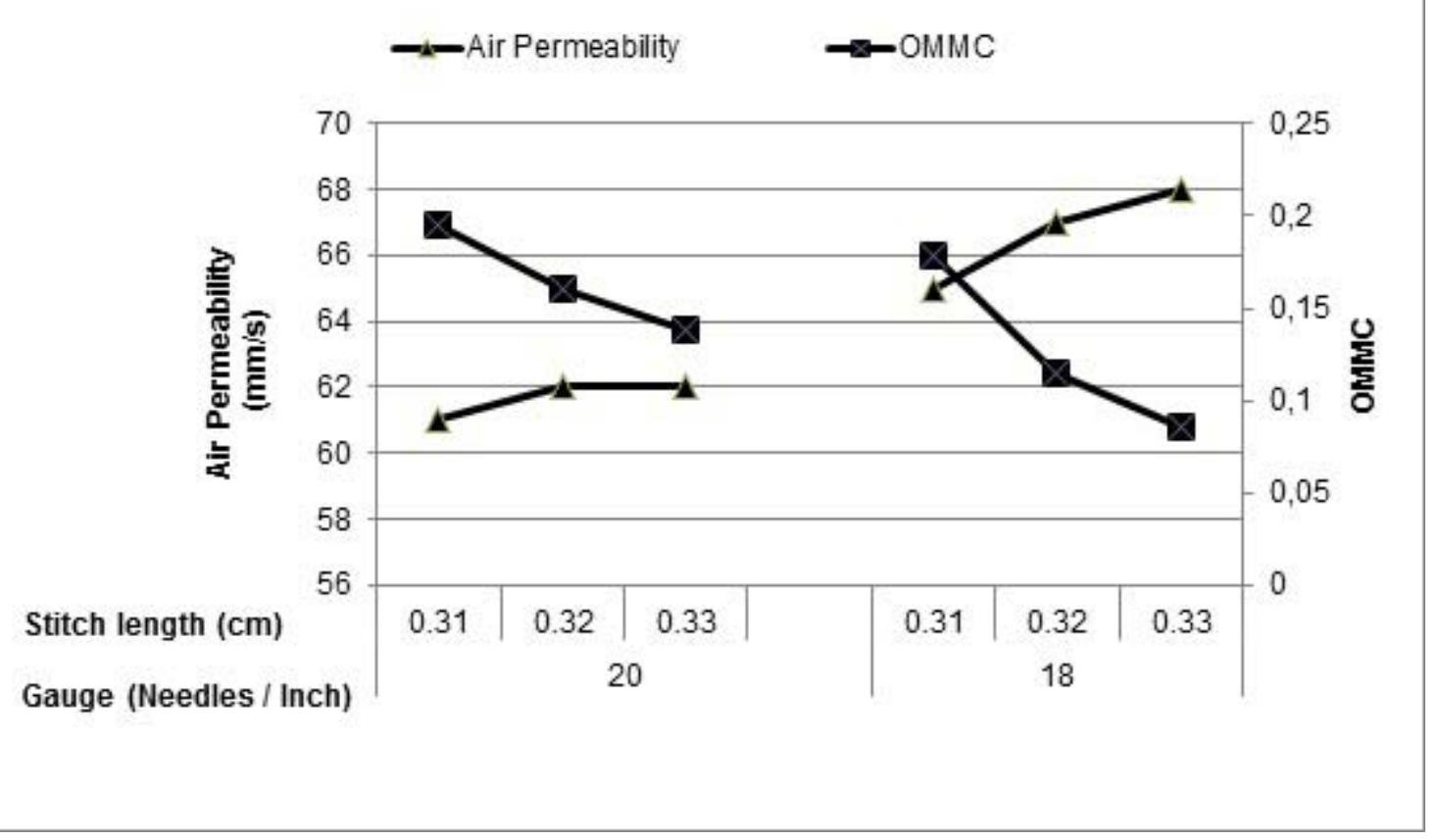

Figure 8. Relation of air permeability and overall moisture management capacity of interlock fabric 
increase in fabric thickness and porosity. The increase in fabric porosity consequently results in increase in fabric air permeability and wetting time with decrease in liquid moisture absorption rate, spreading speed and the maximum wetted radius of the fabric. Overall, increasing the fabric tightness factor by decreasing the stitch length results in improvement in fabric moisture management properties but deterioration of the air permeability of the fabric comprising hygroscopic fibres such as cotton.

\section{References}

[1] Slater, K. (1985). Human comfort. Springfield, III., U.S.A: C.C. Thomas.

[2] Song, G. (2011). Improving Comfort in Clothing. Woodhead Publishing Limited.

[3] Li, Y. and Wong, A. S. (2006). Clothing Biosensory Engineering. Woodhead Publishing Limited.

[4] Das, B., Das, A., Kothari, V., Fangueiro, R., and de Araujo, M. (2007). Moisture transmission through textiles. Part II: Evaluation methods and mathematical modelling. AUTEX Research Journal, 7(3), 194-216.

[5] Dongping, L. and Mai, N. (2009). in Second International Conference on Information and Computing Science, 129-131.

[6] Fangueiro, R., Filgueiras, A., Soutinho, F., and Meidi, $X$. (2010). Wicking Behavior and Drying Capability of Functional Knitted Fabrics. Textile Research Journal, 80(15), 1522-1530.

[7] Advansa. (2010, August,) Advansa adds UPF to ThermoCool. Apparel Magazine. 1.

[8] Onofrei, E., Rocha, A. M., and Catarino, A. (2011). The influence of knitted fabrics' structure on the thermal and moisture management properties. Journal of Engineered Fibers and Fabrics, 6(4), 10-22.

[9] Nida, O. and Arzu, M. (2007). Thermal comfort properties of some knitted structures. Fibres and textiles in Eastern Europe, 15(5), 94-96.

[10] Li, Y. and Zhu, Q. (2003). Simultaneous heat and moisture transfer with moisture sorption, condensation, and capillary liquid diffusion in porous textiles. Textile Research Journal, 73(6), 515-524.
[11] Chidambaram, P., Govind, R., and Venkataraman, K. C. (2011). The effect of loop length and yarn linear density on the thermal properties of bamboo knitted fabric. AUTEX Research Journal, 11(4), 102-105.

[12] Kane, C., Patil, U., and Sudhakar, P. (2007). Studies on the influence of knit structure and stitch length on ring and compact yarn single jersey fabric properties. Textile Research Journal, 77(8), 572-582.

[13] Ibrahim, N., Khalifa, T., El-Hossamy, M., and Tawfik, T. (2010). Effect of knit structure and finishing treatments on functional and comfort properties of cotton knitted fabrics. Journal of Industrial Textiles, 40(1), 49-64.

[14] Bivainyte, A., Mikucioniene, D., and Kerpauskas, P. (2012). Investigation on thermal properties of double-layered weft knitted fabrics. Materials Science, 18(2), 167-171.

[15] Anand, S. C. (2003) Sportswear fabrics. Knitting International. 23-25.

[16] Petrulyte, S. and Baltakyte, R. (2008). Investigation into the wetting phenomenon of terry fabrics. Fibres \& Textiles in Eastern Europe, 16(4), 62-66.

[17] Mikucioniene, D., Ciukas, R., and Mickeviciene, A. (2010). The influence of knitting structure on mechanical properties of weft knitted fabrics. Materials Science, 16(3), 221-225.

[18] Charalambus, $A$. (2007). New approach to a theoretical study of some of the parameters in the knitting process, and their influence on knit-fabric stitch density. AUTEX Research Journal, 7(2), 95-99.

[19] Singh, G., Roy, K., Varshney, R., and Goyal, A. (2011). Dimensional parameters of single jersey cotton knitted fabrics. Indian Journal of Fibre and Textile Research, 36(2), 111-116.

[20] AATCC. (2012). AATCC Test Method 195-2011; Liquid Moisture Management Properties of Textile Fabrics. AATCC Technical Manual, 87, 366-370.

[21] Tugrul, O. R. and Serin, M. M. (2011). Optimization of air permeability of knitted fabrics with the Taguchi approach. The Journal of the Textile Institute, 102(5), 395-404.

[22] Ogulata, R. T. and Mavruz, S. (2010). Investigation of porosity and air permeability values of plain knitted fabrics. Fibres \& Textiles in Eastern Europe, 18(5), 82-90. 